\title{
Diagnostic Values for Club Cell Secretory Protein (CC16) in Serum of Patients of Combined Pulmonary Fibrosis and Emphysema
}

\author{
Nariaki Kokuho, Takeo Ishii, Koichiro Kamio, Hiroki Hayashi, Misuzu Kurahara, Takashi Motegi, Kumiko Hattori, \\ Arata Azuma, Akihiko Gemma, and Kozui Kida
}

\section{Patients and Methods}

\section{Patients}

\section{Study design}

This is a cross-sectional cohort study aiming to test an association of CPFE with four serum biomarkers, CC16, TGF- $\beta 1$, KL-6, and SP-D, among patients who visited the Respiratory Care Clinic or the University Hospital, Nippon Medical School, Tokyo, Japan. Patients were enrolled consecutively to avoid intentional selection.

\section{Study population}

A total of 410 patients were recruited consecutively from November 2003 to March 2008 at the Respiratory Care Clinic (RCC), which is a secondary referral facility affiliated with Nippon Medical School, Tokyo, Japan. The nature of health insurance in Japan allows all individuals to access any health care institution without a referral letter from a primary care physician to the specialist (such as a chest physician-specialist); that is, any individual was able to visit by his or her own choice. Therefore, the individuals who visited RCC were a mixture of those referred to the specialists and those who visited of their own free will. Thus, some patients had already begun pharmacological treatment of COPD, while others had not. A total of 191 patients were excluded because high-resolution computed tomography (HRCT) of the chest was not taken, another 40 patients were excluded because they did not consent to giving blood samples, and one patient was excluded because of a high creatinine level (greater than $1.2 \mathrm{mg} / \mathrm{dL}$ ).

$\mathrm{T}$ to investigate changes in CC16 in lung fibrosis with life-long smoking history, ten smokers with idiopathic pulmonary fibrosis (IPF) who visited the university hospital, Nippon Medical School, Tokyo, Japan from March 2014 to April 2014 were recruited.

\section{Inclusion criteria}

The eligible cohort consisted of patients with both a smoking history and any respiratory symptoms such as cough and/or expectoration for more than 8 weeks or dyspnea on exertion. The patients with a smoking history included current smokers and ex-smokers; however, the patients who never smoked were excluded. The smoking history was based on self-reported information. The number of pack-years was calculated according to the following formula: number of pack-years $=$ (number of cigarettes per day $/ 20) \times$ number of years smoking.

We defined CPFE according to the original report by Cottin and colleagues (E1), as a syndrome characterized by upper-lobe emphysema and pulmonary fibrosis of the lower lungs according to high-resolution computed tomography (HRCT) of the chest. The diagnosis of IPF was confirmed after detailed examinations in accordance with the criteria of ATS/ERS/JRS/ALAT statement (E2). The latter images were reviewed separately by a radiologist and two of the authors who did not have any knowledge of the patients' clinical status; a fourth opinion was sought when there was no consensus among the first three.

\section{Exclusion criteria}

Patients were excluded if a diagnosis was made of any of the following pulmonary diseases: bronchial asthma, bronchiectasis, sinobronchial syndrome, active or old pulmonary tuberculosis, nontuberculous mycobacteriosis, an abnormal chest shadow suggestive of a lung tumor, sleep apnea syndrome, resolved pneumothorax, lymphangioleiomyomatosis, lung cancer, diffuse panbronchiolitis, hypersensitivity pneumonitis, asbestosis, pneumonia, chronic eosinophilic pneumonia, and chronic pulmonary thromboembolism. The diagnoses of these diseases were made by qualified chest physician-specialists in accordance with clinical guidelines, laboratory examinations, bacteriological examinations, and/or histological examinations.

Patients with a diagnosis of any of the following cardiovascular diseases were also excluded: hypertension, ischemic heart disease, arrhythmia, congestive heart failure, atrial septal aneurysm, ventricular septal aneurysm, hypertrophic cardiomyopathy, valvular disease, an atrial septal defect, a ventricular septal defect, and tetralogy of Fallot.

The patients suspected of having any type of interstitial lung diseases received optional examinations to determine if they had an interstitial lung disease of collagen-vascular origin, which included ELISA-based tests for antinuclear antibodies, anti-double-stranded DNA antibodies, rheumatoid factor and antineutrophil cytoplasmic antibodies. Thus, some cases were diagnosed as idiopathic interstitial fibrosis (see later). 


\section{Examinations}

\section{High-resolution computed tomography (HRCT) of the chest}

\section{The extent of the low-attenuation area (\%LAA)}

We determined the extent of the low-attenuation area (\%LAA) by means of HRCT scans, according to the method described by Nakano and co-workers, with a slight modification (E3). Briefly, images of two slices were obtained from the bilateral lungs at upper lobes. The upper slice was located at the aortic arch. HRCT was performed using $1.25-\mathrm{mm}$ collimation, the scan time (rotation time) of 0.8 seconds, $120 \mathrm{kV}$ and $100-600$ $\mathrm{mA}$ on a Light Speed Pro16 CT scanner (GE Co., Tokyo, Japan). The \%LAA was calculated by the scanner on these 2 slices. The arithmetic mean value for each individual was used as a representative value of \%LAA. The cut-off level for LAA was defined as $-960 \mathrm{HU}$. The HRCT of the chest was performed in the supine position, with breath held at full inspiration.

\section{Testing for interstitial lung diseases}

Pulmonary fibrosis was defined by honeycomb appearance, reticular shadow, ground glass opacity and traction bronchiectasis as described previously (E2). Severity of fibrosis on the six slices was scored on the scale of 0 to 5 for interstitial abnormality according to a modified Kazerooni score (right-and-left 3 slices, from 0 to 30).

The score of the fibrosis was defined by the following criteria:

0: No fibrosis

1: Interlobular septal thickening; no discrete honeycombing

2: Honeycombing (with or without septal thickening) involving $<25 \%$ of the lobe

3: Honeycombing (with or without septal thickening) involving $25-49 \%$ of the lobe

4: Honeycombing (with or without septal thickening) involving $50-75 \%$ of the lobe

5: Honeycombing (with or without septal thickening) involving $>75 \%$ of the lobe.

Images of the six slices were obtained from the bilateral lungs at upper, middle, and lower lobes. The upper slice was obtained at the aortic arch, the middle section at the carina, and the lower section approximately $1 \mathrm{~cm}$ above the top of the diaphragm (E4).

\section{Pulmonary function tests}

\section{Lung function}

All patients had baseline and postbronchodilator lung function tested during the first visit; the measurements were performed according to the American Thoracic Society guidelines (E5), using special equipment for lung function testing with computer software (Chestac; Chest Co., Tokyo, Japan) to assess $\mathrm{FEV}_{1}, \mathrm{FVC}, \mathrm{FEV}_{1}$ / FVC ratio, TLC, RV, and carbon monoxide diffusing capacity (DLCO).
COPD was defined as a postbronchodilator forced expiratory volume in 1 second $\left(\mathrm{FEV}_{1}\right)$ or forced vital capacity (FVC) of $<0.7$. Severity classification of COPD was based on the GOLD criteria (E6). The reference values of postbronchodilator $\mathrm{FEV}_{1}$ and $\mathrm{VC}$ were in accordance with the standards of the Japanese Respiratory Society (E7). The patients had to perform at least three acceptable maneuvers. Postbronchodilator percentage of predicted normal $\mathrm{FEV}_{1}$ was calculated using the European Community Coal and Steel scales (ECCS) (E8).

\section{Carbon monoxide}

Carbon monoxide breath test was performed at the first visit to confirm the smoking status of current or exsmokers.

\section{Six-minute walk test}

The 6-minute walk test (6MWT) was conducted at first visit. The supervised standardized 6MWT was performed by all patients. The test was conducted according to ATS standards (E9). During 6MWT, oximetry was performed every 10 seconds with a pulse oximeter (Pulseox; Teijin Co., Tokyo, Japan).

\section{Arterial blood gas analysis}

Arterial blood gas (ABG) levels were tested in a radial artery or femoral artery. The arterial oxygen tension $\left(\mathrm{PaO}_{2}\right)$, carbon dioxide tension $\left(\mathrm{PaCO}_{2}\right)$ and acidity $(\mathrm{pH})$ were measured during the ABG test. The alveolararterial oxygen difference $\left(\mathrm{AaDO}_{2}\right)$ is a measure of the difference between the alveolar (A) and the arterial (a) concentration of oxygen. $\mathrm{AaDO}_{2}$ was calculated according to the following formula: $\mathrm{AaDO}_{2}=150-\left(\mathrm{PaCO}_{2} /\right.$ $\left.0.8-\mathrm{PaO}_{2}\right)$.

\section{Echocardiography}

Echocardiography was performed with the patients in the left lateral recumbent position using a diagnostic ultrasound system (Aplio SSA-770A; Toshiba Medical Systems Co., Tochigi, Japan) with a $2.5-\mathrm{MHz}$ transducer. The procedure was performed by the same experienced echocardiographer for all patients. The data were recorded in the standard parasternal and apical views during normal breathing at end-expiration in accordance with the standards of the American Society of Echocardiography. The left ventricular (LV) internal end-diastolic and endsystolic diameters (LVDd and LVDs) were measured over 5 consecutive cycles. LV diastolic function was evaluated by means of transmitral Doppler recording using the pulse and tissue Doppler techniques with 2-dimensional guidance in the apical 4-chamber view. The systolic pulmonary artery pressure was calculated using the modified Bernoulli equation with the estimated right atrial pressure of $10 \mathrm{mmHg}$ (E10). 


\section{Measurements of serum biomarkers}

\section{Blood samples}

Blood samples for biomarker analysis were collected at first visit. Whole blood was drawn into Vacutainer tubes and serum was prepared by centrifugation at $1500 \times g$ for $10-15 \mathrm{~min}$. The serum samples were stored at $-80^{\circ} \mathrm{C}$ until analysis.

\section{Measurement of serum CC16}

Serum CC16 (range 2-100 ng/mL) was measured in duplicate by operators (who were blinded to the patients' clinical status) using a colorimetric sandwich immunoassay (BioVendor GmbH, Heidelberg, Germany) according to the manufacturer's protocol. The standards, quality controls, and samples were incubated in microplate wells precoated with a polyclonal anti-human club cell protein antibody. After 60-minute incubation and washing, a biotin-labeled polyclonal anti-human club cell protein antibody was added and incubated for 60 minutes.

After another wash, streptavidin-horseradish peroxidase conjugate was added. After 60-minute incubation and the last washing step, the attached conjugate was allowed to react with the substrate solution (TMB). The reaction was stopped by addition of an acidic solution and absorbance of the resulting yellow product was measured. The absorbance is proportional to the concentration of the club cell protein. A standard curve was constructed by plotting absorbance values against concentrations of the standards, and concentrations of unknown samples were determined using this standard curve.

\section{Measurement of serum transforming growth factor $\beta 1$}

Serum concentration of TGF- $\beta 1$ was determined using an enzyme-linked immunosorbent assay (ELISA). The Quantikine Human TGF- $\beta 1$ Immunoassay kit (R\&D Systems, Minneapolis, MN, USA) was used according to the manufacturer's instructions. Assays were carried out in duplicate for each sample by operators who were blinded to the patients' clinical status.

The microplates had been precoated with a monoclonal antibody specific to TGF- $\beta 1$. Standards, controls, and samples were pipetted into the wells and the TGF$\beta 1$ present in the solution was bound by the immobilized antibody. After several washes, an enzyme-linked polyclonal antibody specific to TGF- $\beta 1$ was added to the wells to form a sandwich with the TGF- $\beta 1$ molecule immobilized during the first incubation. Following a wash, a substrate solution was added to the wells, and color developed in proportion to the amount of TGF$\beta 1$ bound in the initial step. The color development was stopped, and the absorbance was measured.

\section{Measurement of serum Krebs von den Lungen- 6 and surfactant protein D}

Serum KL-6 levels were measured using a sandwichtype electrochemiluminescence immunoassay (ECLIA) on a Picolumi 8220 Analyser (Sanko Junyaku, Tokyo, Japan), as described previously (E11). The serum sample was incubated with anti-KL-6 antibody-coated magnetic beads prior to separation using a magnetic rack. A ruthenium-labeled anti-KL-6 antibody was then added to the beads as a second antibody following a wash with PBS. The reaction mixture was placed into the electrode, and the photons emitted from the ruthenium were detected by a photomultiplier.

Specific ELISA kits were used for the measurement of SP-D (Yamasa, Chiba, Japan) (E12) according to the manufacturer's instructions. Briefly, polystyrene cups coated with an anti-SP-D antibody were incubated with $20 \mu \mathrm{L}$ of 11 -fold-diluted serum at $4^{\circ} \mathrm{C}$ for 24 hours. The cups were then washed and incubated at $25^{\circ} \mathrm{C}$ for 2 hours with $100 \mu \mathrm{L}$ of a 111-fold-diluted horseradish peroxidase-conjugated anti-SP-D antibody. Next, the cups were washed again, and $100 \mu \mathrm{L}$ of tetramethylbenzidine was added and incubated at $25^{\circ} \mathrm{C}$ for 15 minutes. Finally, $2 \mathrm{mmol} / \mathrm{L}$ of $\mathrm{NaN}_{3}$ was added to terminate the peroxidase reaction, and the absorbance at $450 \mathrm{~nm}$ was measured. Serum SP-D levels $>2 \times$ SD above the mean level in the healthy controls were considered elevated.

\section{Statistical analysis}

The results of basic and pulmonary function tests were presented as mean \pm standard deviation for all values. Statistical analysis was in the form of ANOVA. Serum CC16 and TGF- $\beta 1$ concentrations were processed to obtain the mean \pm standard error and compared among the three groups using a Kruskal-Wallis signed-rank test with the Tukey-Kramer post-hoc test. Multiple linear regression was employed to select the variables (age, gender, smoking status, and creatinine) that affect CC16 in multivariate analyses (E13).

The results of the KL-6, CC16, and SP-D assays were compared among the three groups using Receiver Operator Characteristic (ROC) analysis. The same was done with combinations of 2-3 biomarkers. The three combinations of biomarkers were "KL-6 and CC16," "SP-D and CC16" and "KL-6, SP-D, and CC16" The area under the curve (AUC) of ROC was calculated, and it ranged from 0 to 1 , with 1 indicating perfect discrimination and 0.5 , indicating chance discrimination. AUC values greater than 0.8 were obtained, which is suggestive of good diagnostic capacity of the biomarker assays.

Data were analyzed using the JMP software, Version 9.0.3 for Windows (SAS Institute Inc.). Differences with $p$ values less than 0.05 were considered statistically significant. 


\section{Results}

ETable 1. Basic characteristics of the three groups

\begin{tabular}{|c|c|c|c|c|c|}
\hline & $\begin{array}{l}\text { Smoker control } \\
\quad(n=36)\end{array}$ & $\begin{array}{l}\text { Emphysema } \\
\text { alone }(n=115)\end{array}$ & $\begin{array}{c}\text { CPFE } \\
(n=27)\end{array}$ & $\begin{array}{c}\text { All } \\
(n=178)\end{array}$ & $p$ value \\
\hline Age, years & $64.5 \pm 10.3$ & $67.4 \pm 8.9$ & $74.9 \pm 7.7$ & $68.0 \pm 9.5$ & $<0.0001$ \\
\hline Gender, M/F & $30 / 6$ & $109 / 6$ & $24 / 3$ & $163 / 15$ & NS \\
\hline Pack-years & $42.5 \pm 27.8$ & $78.7 \pm 47.2$ & $91.1 \pm 56.8$ & $73.5 \pm 47.9$ & 0.0005 \\
\hline COPD/non-COPD & $15 / 21$ & $104 / 11$ & $14 / 13$ & $133 / 45$ & $<0.0001$ \\
\hline GOLD I / II / III / IV & $6 / 6 / 3 / 0$ & $10 / 42 / 41 / 11$ & $6 / 4 / 4 / 0$ & $22 / 52 / 48 / 11$ & 0.0042 \\
\hline Ave. Upper LAA & $16.6 \pm 11.8$ & $38.5 \pm 15.7$ & $30.9 \pm 18.1$ & $32.9 \pm 17.6$ & $<0.0001$ \\
\hline $\mathrm{KL}-6$ & $268.4 \pm 95.6$ & $383.7 \pm 227.0$ & $582.1 \pm 314.9$ & $390.5 \pm 241.3$ & $<0.0001$ \\
\hline SP-D & $62.2 \pm 35.3$ & $60.4 \pm 43.1$ & $117.3 \pm 77.0$ & $69.9 \pm 52.7$ & $<0.0001$ \\
\hline
\end{tabular}

The data were analyzed using ANOVA and are presented in the table as mean \pm SD (range). M: male, F: female, COPD: chronic obstructive pulmonary disease, GOLD: global initiative for chronic obstructive lung disease, LAA: Iow attenuation area, KL-6: Krebs von den Lungen 6, SP-D: surfactant protein D and NS: not significant.

ETable 2. Pulmonary function tests and clinical manifestations

\begin{tabular}{|c|c|c|c|c|c|}
\hline & $\begin{array}{l}\text { Smoker } \\
\text { control } \\
(n=36)\end{array}$ & $\begin{array}{l}\text { Emphysema } \\
\text { alone }(n=115)\end{array}$ & $\begin{array}{l}\text { CPFE } \\
(n=27)\end{array}$ & $\begin{array}{c}\text { All } \\
(n=178)\end{array}$ & $p$ value \\
\hline FVC \% & $3.58 \pm 0.93$ & $3.29 \pm 0.82$ & $3.07 \pm 0.75$ & $3.32 \pm 0.84$ & NS \\
\hline $\mathrm{FEV}_{1} / \mathrm{FVC} \%$ & $73.7 \pm 9.3$ & $51.7 \pm 13.7$ & $68.7 \pm 18.4$ & $58.7 \pm 16.8$ & $<0.0001$ \\
\hline $\mathrm{FEV}_{1} \%$ pred & $93.6 \pm 20.2$ & $60.3 \pm 22.3$ & $82.4 \pm 24.1$ & $70.4 \pm 26.1$ & $<0.0001$ \\
\hline TLC & $6.09 \pm 1.26$ & $6.16 \pm 1.08$ & $5.30 \pm 0.96$ & $6.02 \pm 1.14$ & 0.0015 \\
\hline RV /TLC \% & $117.8 \pm 27.1$ & $123.9 \pm 25.6$ & $102.0 \pm 20.9$ & $2.70 \pm 0.80$ & 0.0004 \\
\hline DLC0 \% & $112.6 \pm 23.5$ & $75.7 \pm 22.8$ & $62.4 \pm 21.9$ & $81.2 \pm 28.1$ & $<0.0001$ \\
\hline DLCO/NA \% & $90.5 \pm 15.4$ & $56.6 \pm 17.3$ & $53.7 \pm 20.2$ & $63.0 \pm 22.3$ & $<0.0001$ \\
\hline $\mathrm{PaO}_{2}$ at rest & $89.2 \pm 8.5$ & $81.5 \pm 9.5$ & $85.1 \pm 10.3$ & $83.7 \pm 9.9$ & 0.0002 \\
\hline $\mathrm{PaCO}_{2}$ at rest & $40.9 \pm 3.3$ & $39.8 \pm 4.1$ & $41.4 \pm 3.0$ & $40.2 \pm 3.8$ & NS \\
\hline $\mathrm{AaDO}_{2}$ & $9.7 \pm 8.4$ & $18.8 \pm 10.9$ & $13.2 \pm 10.7$ & $16.0 \pm 11.0$ & $<0.0001$ \\
\hline LVEF & $69.7 \pm 5.0$ & $68.5 \pm 6.1$ & $68.5 \pm 5.7$ & $68.8 \pm 5.8$ & NS \\
\hline Systolic PAP\# & $30.7 \pm 5.2$ & $34.9 \pm 6.9$ & $35.0 \pm 8.3$ & $34.1 \pm 7.0$ & 0.0127 \\
\hline
\end{tabular}

The data were analyzed using ANOVA and are presented in the table as mean \pm SD (range). FVC: forced vital capacity, FEV : forced expiratory volume in one second, TLC: total lung capacity, $\mathrm{RV}$ : residual volume, $\mathrm{DLCO}$ : diffusing capacity of the lung, $\mathrm{VA}$ : alveolar volume, $\mathrm{PaO}_{2}$ : partial pressure of oxygen in arterial blood, $\mathrm{PaCO}_{2}$ : partial pressure of carbon dioxide in arterial blood, $\mathrm{AaDO}_{2}$ : Alveolar-arterial oxygen difference, LVEF: left ventricular ejection fraction, PAP: pulmonary artery pressure, ": assessed by echocardiography and NS: not significant.

ETable 3. Six-minute walk test

\begin{tabular}{|c|c|c|c|c|c|}
\hline & $\begin{array}{l}\text { Smoker control } \\
\qquad(\mathrm{n}=36)\end{array}$ & $\begin{array}{l}\text { Emphysema alone } \\
\qquad(\mathrm{n}=115)\end{array}$ & $\begin{array}{c}\text { CPFE } \\
(n=27)\end{array}$ & $\begin{array}{c}\text { All } \\
(n=178)\end{array}$ & $p$ value \\
\hline Distance & $527.4 \pm 68.8$ & $469.3 \pm 86.2$ & $426.1 \pm 87.8$ & $474.5 \pm 88.3$ & $<0.0001$ \\
\hline Pre $\mathrm{SpO}_{2}$ & $96.8 \pm 1.1$ & $95.9 \pm 1.6$ & $95.7 \pm 1.8$ & $96.1 \pm 1.6$ & 0.0024 \\
\hline Last $\mathrm{SpO}_{2}$ & $96.0 \pm 1.3$ & $91.1 \pm 5.4$ & $90.1 \pm 6.6$ & $91.9 \pm 5.5$ & $<0.0001$ \\
\hline$\Delta \mathrm{SpO}_{2}$ & $0.9 \pm 1.2$ & $4.8 \pm 5.0$ & $5.5 \pm 5.3$ & $4.1 \pm 4.8$ & $<0.0001$ \\
\hline Mini $\mathrm{SpO}_{2}$ & $94.7 \pm 1.4$ & $90.0 \pm 5.3$ & $89.5 \pm 6.4$ & $90.9 \pm 5.3$ & $<0.0001$ \\
\hline Borg Scale & $1.8 \pm 1.5$ & $3.1 \pm 2.0$ & $3.1 \pm 2.1$ & $2.9 \pm 2.0$ & 0.0019 \\
\hline Leg fatigue & $1.9 \pm 1.8$ & $1.8 \pm 1.6$ & $2.3 \pm 1.9$ & $1.9 \pm 1.7$ & NS \\
\hline Pre HR & $80.9 \pm 14.7$ & $84.3 \pm 14.4$ & $83.9 \pm 7.8$ & $83.5 \pm 13.6$ & NS \\
\hline Max HR & $115.6 \pm 15.5$ & $117.2 \pm 14.0$ & $112.2 \pm 13.5$ & $116.0 \pm 14.2$ & NS \\
\hline$\Delta H R$ & $34.7 \pm 15.0$ & $32.9 \pm 16.1$ & $28.3 \pm 11.0$ & $32.5 \pm 15.2$ & NS \\
\hline Recovery time & $130.7 \pm 59.3$ & $125.2 \pm 63.7$ & $116.1 \pm 56.3$ & $124.8 \pm 61.3$ & NS \\
\hline
\end{tabular}

The data were analyzed using ANOVA and are presented in the table as mean $\pm \mathrm{SD}$ (range). $\mathrm{SpO}_{2}$ : saturation of pulse oximetry oxygen, HR: heart rate and NS: not significant. 
ETable 4. The data on AUC, sensitivity and specificity, and the threshold of the biomarkers

\begin{tabular}{lccc}
\hline Figure & A & B & C \\
\hline AUC $(95 \% \mathrm{Cl})$ & 0.828 & 0.804 & 0.813 \\
& $(0.721-0.899)$ & $(0.691-0.883)$ & $(0.698-0.891)$ \\
Sensitivity (\%) & 74.07 & 69.23 & 76.92 \\
Specificity (\%) & 86.75 & 79.41 & 75.00 \\
KL-6 (U/ml) & 500 & - & 551 \\
SP-D (ng/ml) & - & 78.1 & 35.8 \\
CC16 (ng/ml) & 7.57 & 7.11 & 8.09
\end{tabular}

AUC: area under the curve; Cl: confidence interval; KL-6: Krebs von den Lungen 6; SP-D: surfactant protein D and CC16: club cell secretory protein 16.

ETable 5. Pulmonary function tests and clinical manifestations of patients with IPF

\begin{tabular}{|c|c|}
\hline & $\operatorname{IPF}(n=10)$ \\
\hline Age, years & $71.8 \pm 4.6$ \\
\hline Gender, M/F & $8 / 2$ \\
\hline Pack-years & $37.8 \pm 20.2$ \\
\hline $\mathrm{KL}-6$ & $1128.8 \pm 556.3$ \\
\hline SP-D & $134.9 \pm 68.4$ \\
\hline CC16 & $22.2 \pm 4.7$ \\
\hline FVC & $2.5 \pm 0.7$ \\
\hline $\mathrm{FVC} \%$ & $83.0 \pm 18.3$ \\
\hline $\mathrm{FEV}_{1}$ & $2.2 \pm 0.6$ \\
\hline $\mathrm{FEV}_{1} / \mathrm{FVC}$ & $89.4 \pm 9.3$ \\
\hline $\mathrm{FEV}_{1} \%$ predicted & $100.6 \pm 17.1$ \\
\hline DLCO $\%$ & $71.2 \pm 27.3$ \\
\hline DLCO/NA\% & $77.3 \pm 17.4$ \\
\hline Systolic PAP\# & $34.6 \pm 7.2$ \\
\hline
\end{tabular}

The data are presented in the table as means $\pm \mathrm{SD}$ (range).

M: male, F: female, KL-6: Krebs von den Lungen 6, SP-D: surfactant protein D, CC16: club cell 16, FVC: forced vital capacity, FEV1: forced expiratory volume in one second, DLCO: diffusing capacity of the lung, VA: alveolar volume: left ventricular ejection fraction, PAP: pulmonary artery pressure, ": assessed by echocardiography.

\section{References}

E1. Cottin V, Nunes H, Brillet PY, Delaval P, Devouassoux G, Tillie-Leblond I, Israel-Biet D, Court-Fortune J, Valeyre D, Cordier JF, Groupe d'Etude et de Recherche sur les Maladies Orphelines Pulmonaires (GERM O P). Combined pulmonary fibrosis and emphysema: a distinct underrecognised entity. Eur Respir J 2005; 26:586-593.

E2. Raghu G, Collard HR, Egan JJ, Martinez FJ, Behr J, Brown KK, Colby TV, Cordier JF, Flaherty KR, Lasky JA, Lynch
DA, Ryu JH, Swigris JJ, Wells AU, Ancochea J, Bouros D, Carvalho C, Costabel U, Ebina M, Hansell DM, Johkoh R, Kim DS, King TE Jr, Kondoh Y, Myers J, Muller NL, Nicholson AG, Richeldi L, Selman M, Dudden RF, Griss BS, Protzko SL, Schunemann HJ, ATS/ERS/JRS/ALAT Committee on Idiopathic Pulmonary Fibrosis. An official ATS/ERS/JRS/ ALAT statement: idiopathic pulmonary fibrosis: evidencebased guidelines for diagnosis and management. Am J Respir Crit Care Med 2011; 183:788-824.

E3. Nakano Y, Muro S, Sakai H, Hirai T, Chin K, Tsukino M, Nishimura K, Itoh $\mathrm{H}$, Paré PD. Computed tomographic measurements of airway dimensions and emphysema in smokers. Correlation with lung function. Am J Respir Crit Care Med 2000; 162:1102-1108.

E4. Kazerooni EA, Martinez FJ, Flint A, Jamadar DA, Gross BH, Spizarny DL, Cascade PN, Whyte RI, Lynch JP 3rd, Toews G. Thin-section CT obtained at $10-\mathrm{mm}$ increments versus limited three-level thin-section CT for idiopathic pulmonary fibrosis: correlation with pathologic scoring. AJR Am J Roentgenol 1997; 169:977-983.

E5. American Thoracic Society. Standardization of spirometry, 1994 update. Am J Respir Crit Care Med 1995; 152:1107-1136.

E6. Global Initiative for Chronic Obstructive Lung Disease (GOLD) 2013: Global strategy for the diagnosis, management, and prevention of chronic obstructive pulmonary disease. Available from: http://www.goldcopd.org/ [accessed 2014 September 4].

E7. Japanese Respiratory Society. (The predicted values of spirometry and arterial blood gas analysis in Japanese). J Jpn Resp Soc 2001; 39: Appendix.

E8. Quanjer PH, Tammeling GJ, Cotes JE, Pedersen OF, Peslin $\mathrm{R}$, Yernault JC. Lung volumes and forced ventilatory flows. Report Working Party Standardization of Lung Function Tests, European Community for Steel and Coal. Official Statement of the European Respiratory Society. Eur Respir J Suppl 1993; $16: 5-40$.

E9. ATS Committee on Proficiency Standards for Clinical Pulmonary Function Laboratories. ATS statement: guidelines for the six-minute walk test. Am J Respir Crit Care Med 2002; 166:111-117.

E10. Yock PG, Popp RL. Noninvasive estimation of right ventricular systolic pressure by Doppler ultrasound in patients with tricuspid regurgitation. Circulation 1984; 70:657-662.

E11. Yokoyama A, Kondo K, Nakajima M, Matsushima T, Nishimura M, Bando M, Sugiyama Y, Totani Y, Ishizaki T, Ichiyasu H, Suga M, Hamada H, Kohno N. Prognostic value of circulating KL-6 in idiopathic pulmonary fibrosis. Respirology 2006; 11:164-168.

E12. Nagae H, Takahashi H, Kuroki Y, Honda Y, Nagata A, Ogasawara Y, Abe S, Akino T. Enzyme-linked immunosorbent assay using $F\left(a b^{\prime}\right) 2$ fragment for the detection of human pulmonary surfactant protein D in sera. Clin Chim Acta 1997; 266:157-171.

E13. Lomas DA, Silverman EK, Edwards LD, Miller BE, Coxson HO, Tal-Singer R. Evaluation of COPD Longitudinally to Identify Predictive Surrogate Endpoints (ECLIPSE) investigators. Evaluation of serum CC-16 as a biomarker for COPD in the ECLIPSE cohort. Thorax 2008; 63:1058-1063. 